\title{
The capillary plexus in the gas exchange zone of human neonatal lung: an ultrastructural study
}

\author{
JAMES C DORNAN, COWAN MEBAN \\ From the Departments of Midwifery and Anatomy, Queen's University, Belfast
}

\begin{abstract}
The structure of the capillary plexus in the gas exchange zone in the lungs of five neonates was investigated by electron microscopy and cytochemical techniques. The results show that the capillaries associated with the terminal respiratory saccules are narrow and that they generally possess two to three endothelial cells per cross section. "Seamless" and protoplasmic capillaries were not observed. A capillary plexus was located on either side of each intersaccular septum and the mesh size of this plexus was relatively large. The gas diffusion pathway in the neonatal lung was found to be very short (mean $1.84 \mu \mathrm{m}$ ). It is suggested that the layer of periodate reactive material lining the luminal surfaces of the capillary endothelial cells may have important functions in vivo.
\end{abstract}

Our knowledge of the fine structure of the tissues forming the gas exchange zone in the neonatal human lung is still very incomplete. Studies using the electron microscope have contributed much information on the changes that occur in animal lungs during the perinatal period (for reviews see Burri and Weibel, ${ }^{1}$ Meyrick and Reid ${ }^{2}$ ); in contrast, the few published reports on the ultrastructure of human neonatal lung have been concerned mainly with pathological conditions. ${ }^{3-5}$

In recent years we have procured a sizeable collection of lung samples from human fetuses and neonates. Some of these tissues were obtained soon after death and are thus suitable for electron microscopic investigations. This paper describes the microstructure of the capillary plexus associated with the gas exchange zone in the lungs of five newborn babies.

\section{Methods}

The human lung tissues used in this study were obtained from a small series of neonates (table 1). In each case a postmortem examination was performed as soon as the parents had given their written consent.

Small blocks of peripheral lung tissue were dissected out and fixed in $2.5 \%$ glutaraldehyde in 0.1

Address for reprint requests: Professor C Meban, Department of Anatomy, Medical Biology Centre, Belfast BT9 7BL.

Accepted 18 April 1985 mol/l cacodylate buffer ( $\mathrm{pH} 7.35$ ) for two hours at $4^{\circ} \mathrm{C}$. The blocks were washed in a $7 \%$ sucrose cacodylate buffer solution, postfixed in buffered $2 \%$ osmium tetroxide, dehydrated in ethanol, and embedded in Durcupan resin. Thin sections (50-70 nm) were stained with uranyl acetate and lead citrate and examined in a JEOL-100CX electron microscope. Twenty fields were selected at random in the sections from each lung and photographed at two magnifications $(\times 3200$ and $\times 10000)$. Estimates of the arithmetic mean values of the parameters listed in table 2 were obtained either by direct measurement or by use of the morphometric procedures described by Weibel and Knight. ${ }^{\circ}$

Some blocks of lung tissue were stained according to the periodic acid-chromic acid-phosphotungstic acid procedure of Rambourg et al..$^{7}$ Other specimens were stained with colloidal iron oxide according to the method previously described by Meban. ${ }^{8}$ Control tissues were methylated by exposure to thionyl chloride (2\% in absolute methanol) for four hours at room temperature or to acidified methanol $(0.1 \mathrm{~N}$ hydrochloride in absolute methanol) for 12 hours at $60^{\circ} \mathrm{C}$. These control specimens were then stained with colloidal iron oxide and processed for electron microscopy by the standard procedure.

\section{Results}

All of the tissues used in this study were sufficiently well preserved to allow the recognition of their main structural components. The specimens from the different babies showed similar features. 
Table 1 Details of the neonates studied

\begin{tabular}{llll}
\hline Case no & $\begin{array}{l}\text { Age (w) since last } \\
\text { menstrual period }\end{array}$ & $\begin{array}{l}\text { Body weight } \\
(\mathrm{g})\end{array}$ & $\begin{array}{l}\text { Cause of death/ } \\
\text { malformations }\end{array}$ \\
\hline 1 & 39 & 2000 & $\begin{array}{l}\text { Meningomyelocele and exomphalos } \\
\text { Encephalocele } \\
\text { Intrapartum death; } \\
\text { no malformations }\end{array}$ \\
2 & 38 & 3380 & $\begin{array}{c}\text { Anencephaly (twin pregnancy) } \\
\text { Arthrogryphosis multiplex }\end{array}$ \\
4
\end{tabular}

The distal portion of each lung was largely composed of terminal respiratory saccules (fig 1). Rudimentary alveoli were represented by shallow depressions in the walls of these saccules and short ridges ("secondary septa") indicated the sites where interalveolar septa were developing (fig 2). The intersaccular ("primary") septa had relatively thick cores of connective tissue. The two surfaces of each intersaccular septum contained a plexus of capillaries. These plexuses were continuous with the plexus within the developing interalveolar septa. Some of the capillaries bulged out into the saccule lumen; others were countersunk into the substance of the septa (figs 1 and 3).

The morphometric data (table 2) show that the mean diameter of the capillary profiles was $9.22 \mu \mathrm{m}$ and the mean thickness of the air-blood barrier was $1.84 \mu \mathrm{m}$. Measurements of intercapillary distance (that is, the linear distance between the centres of adjacent capillary profiles) ranged from 9.30 to 30.10 (mean 22.2) $\mu \mathrm{m}$.

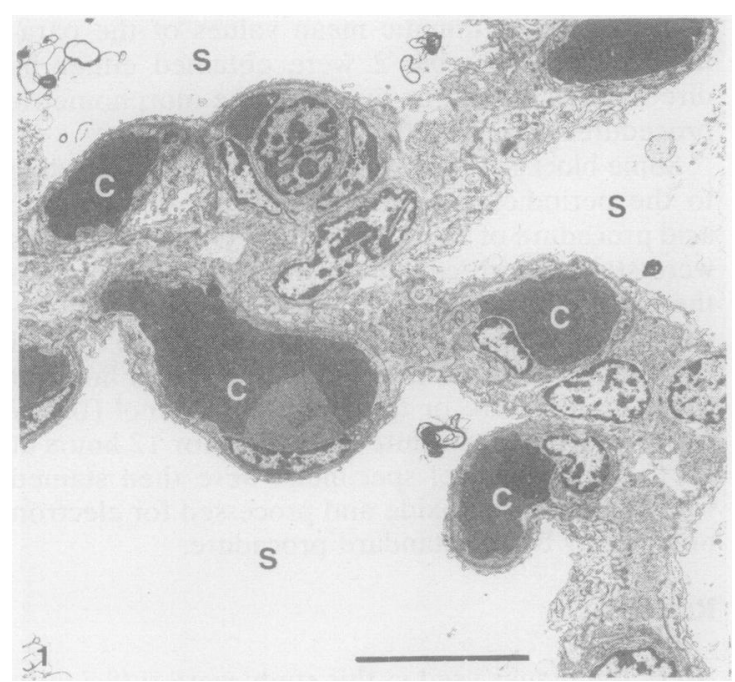

Fig 1 Section through the intersaccular septa of a neonate. C-pulmonary capillary (containing an erythrocyte); $S$-lumen of a terminal respiratory saccule. The bar represents $10 \mu \mathrm{m}$.
Examination of micrographs of the intersaccular walls sectioned in random directions confirmed that the wall of each pulmonary capillary was formed by two to three endothelial cells. A typical endothelial cell consisted of two parts: a relatively thick zone that contained the nucleus and a thinner sheet of cytoplasm that constituted a sizeable area of the vessel wall (figs 3 and 4). The perinuclear portions of the cells were most frequently found in the deeper aspect of the septa; in a proportion of cases (10 $15 \%)$, however, endothelial nuclei were located in areas of the capillary wall adjacent to the saccular air spaces (figs 1 and 3). The intercellular junctions of the endothelium consisted of zonulae occludentes ("tight junctions"). In these zones the limited region of fusion of the plasma membranes was located near the luminal end of the intercellular cleft. A few cross sections of capillaries did not show any interendothelial contacts. In each of these micrographs the vessel profile was usually oval and the plasma membranes were cut obliquely. Consequently these appearances were considered to arise from tangential sectioning of a loop or arc shaped segment of the capillary plexus. Examination of serial sections invariably confirmed this impression.

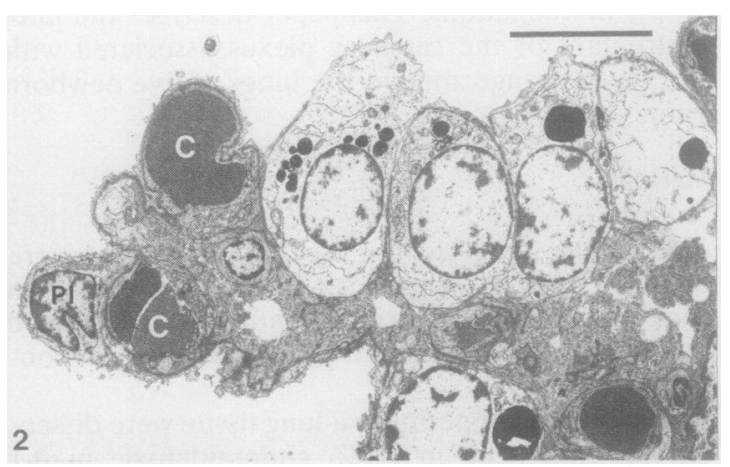

Fig 2 Section through a secondary septum (a developing interalveolar septum). C-pulmonary capillary; P1-type 1 (squamous) pneumocyte. The large, pale cells in the upper part of the septum are type 2 pneumocytes; their osmiophilic inclusions are believed to be stores of pulmonary surfactant. The bar represents $10 \mu \mathrm{m}$. 


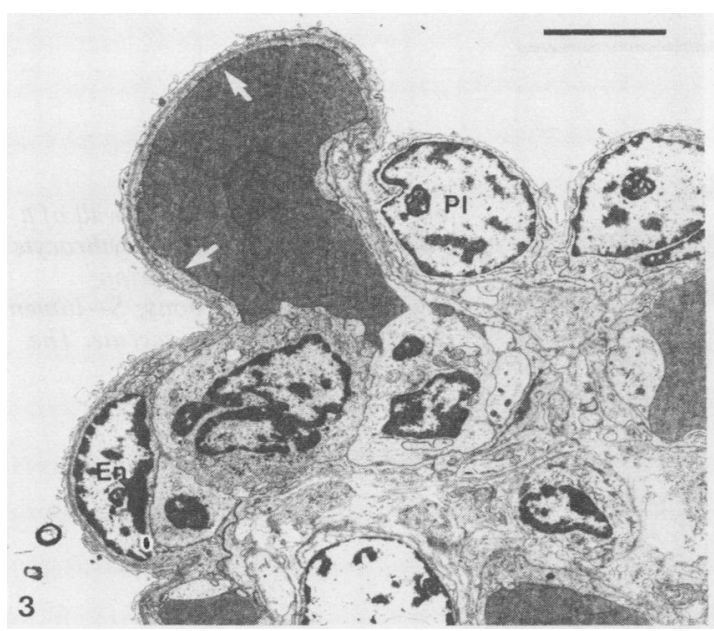

Fig 3 Section through the wall of a respiratory saccule. En-nucleus of a capillary endothelial cell; P1-nucleus of a type 1 pneumocyte (a cytoplasmic sheet of these cells covers the outer surface of the adjacent capillary); arrows indicate the thin sheet of endothelium lining the capillary. The bar represents $5 \mu \mathrm{m}$.

Thin cytoplasmic sheets of endothelium formed the inner layer of the air-blood barrier (fig 5). These sheets had a mean thickness of $0.87 \mu \mathrm{m}$ but very attenuated areas $(0.10 \mu \mathrm{m})$ were frequently encountered. Despite this attenuation pores or fenestrations were not observed. A basal lamina was associated with the endothelium in all of the sections studied. The basal lamina generally appeared as a homogeneous layer of moderate electron density. In the thinner parts of the air-blood barrier (that is, areas with an overall barrier thickness of $<1.0 \mu \mathrm{m}$ ) the laminae of the capillary endothelium and the resipiratory epithelium were fused (fig 5 ). Tissues fixed at different times after death all displayed this fusion of the laminae; consequently the appearance is unlikely to be an artefact produced by postmortem degeneration.

The enduthelial cells contained various organelles, the most conspicuous being mitochondria, small

Table 2 Measurements of capillary plexus dimensions

\begin{tabular}{lc}
\hline Measurement & $\begin{array}{l}\text { Arithmetic mean }(S E) \\
(\mu \mathrm{m})^{*}\end{array}$ \\
\hline $\begin{array}{l}\text { Intercapillary distance } \\
\text { Capillary profile diameter } \\
\text { Total thickness of air-blood } \\
\text { barrier }\end{array}$ & $22.02(1.71)$ \\
$\begin{array}{l}\text { Thickness of endothelial } \\
\text { component of air-blood } \\
\text { barrier }\end{array}$ & $9.22(1.12)$ \\
\hline
\end{tabular}

${ }^{*}$ Pooled data from lung specimens of five neonates. dense bodies, and elements of endoplasmic reticulum. Palade-Weibel bodies were observed infrequently (fig 4). Micropinocytotic vesicles were present throughout the cytoplasm and pinocytotic pits were particularly prominent at the abluminal surface of the attenuated areas (fig 5).

The capillary endothelium showed prominent staining with the periodic acid-chromic acidphosphotungstic acid procedure. An electron dense layer of about $200 \mathrm{~nm}$ in thickness was bound to the luminal plasma membranes in all areas (fig 6). No appreciable staining was observed in specimens that had not been oxidised by the periodic acid and chromic acid. Colloidal iron oxide was also avidly bound to the endothelium (fig 7). Although the relatively large size of the particles hindered the visualisation of very fine detail, sufficient resolution was obtained to verify that the stain was attached to the "outer" (that is, luminal) leaflet of the cell membrane. Pretreatment of control sections with acidified methanol or thionyl chloride eliminated the staining reaction (fig 8 ).

\section{Discussion}

It is exceedingly difficult to obtain samples of human lung tissue that display all of the "normal" ultrastructural features. Even biopsy specimens obtained at thoracotomy from a healthy region of the lung show some artefacts due to the interruption of their blood supply or to physical damage during their dissection. The tissues used in the present investigation were taken from newborn babies as soon as possible (under 30 minutes) after death. The development of the pulmonary vasculature is not considered to have been appreciably affected by the malformations present in these neonates. Furthermore, the tissue preservation was sufficiently good to permit the study of the main ultrastructural components of the gas exchange zone.

There is now wide agreement that important variations exist in the microstructure of the capillaries in different organs. ${ }^{9-11}$ The pulmonary capillaries of the human neonate are characteristically narrow and they contain parts of two to three endothelial cells per cross section. Despite an extensive search, no examples of "seamless" capillaries (vessels having no interendothelial contacts) or protocapillaries (channels enclosed by only one endothelial cell) were found. As in the adult pulmonary circulation, the endothelium lacks pores and fenestrations.

The general layout of the capillary plexus in the lungs of the human neonate differs considerably from that of adult human lung. Each intersaccular septum in the neonatal lung (the main type of partition) has a separate capillary network on both of its 


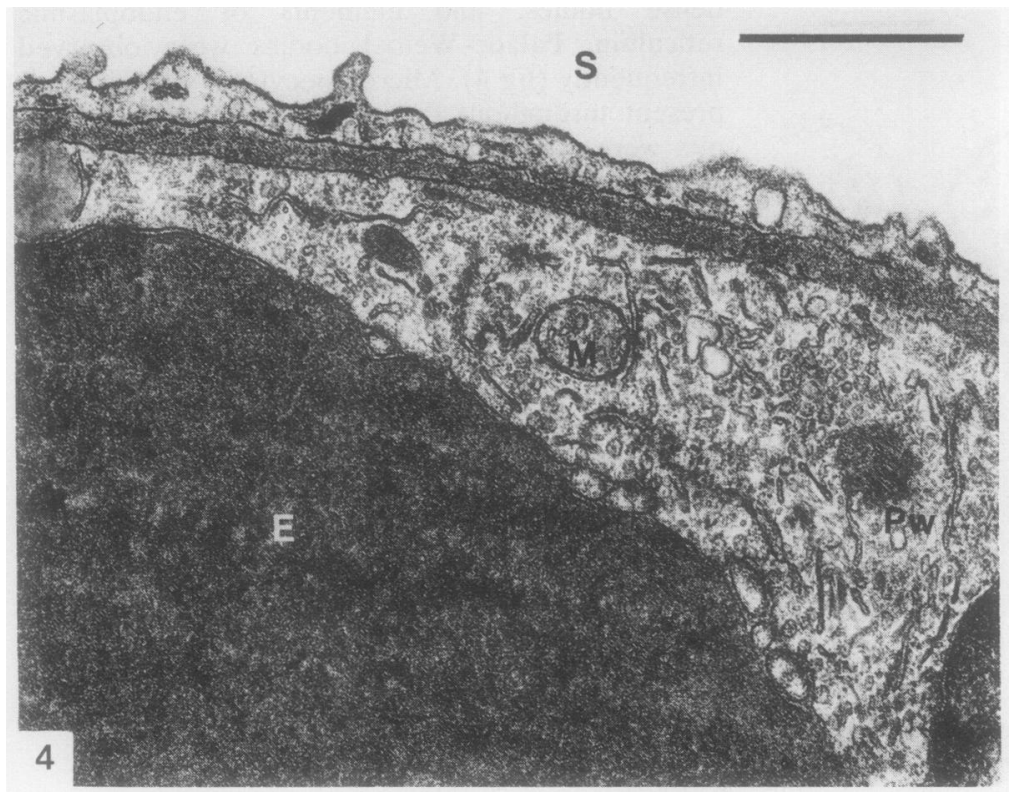

Fig 4 Section through the wall of a pulmonary capillary. E-erythrocyte in lumen; $M-$ mitochondrion; $P w$-Palade-Weibel body; $S$-lumen of terminal respiratory saccule. The bar represents $0 \cdot 1 \mu \mathrm{m}$.

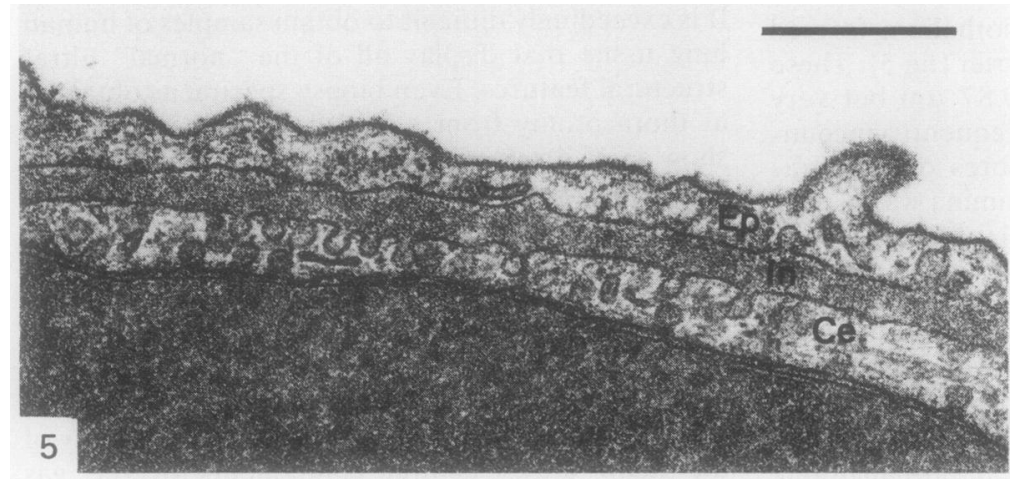

Fig 5 Section through the air-blood barrier. $\mathrm{Ce}$-capillary endothelium; Ep-attenuated layer of respiratory epithelium; In-interstitial layer. The bar represents $0.1 \mu \mathrm{m}$.

surfaces; in contrast, each interalveolar septum in the adult lung contains only a single capillary network. Obviously the arrangement in the neonate could be considered to be primitive in design and possibly less efficient in function. The neonatal system is, however, a temporary arrangement that permits later modification in response to the development of true alveoli and interalveolar septa. The total gas exchange surface of the human neonate has been estimated ${ }^{12}$ to be about $2.8 \mathrm{~m}^{2}$, while the corresponding value in the adult ${ }^{1314}$ is about 82 $\mathrm{m}^{2}$. The way in which this remarkable increase in surface area is matched by an appropriate increase in the bulk of the pulmonary vascular system has yet to be determined.
It is important to bear in mind that the tissues used in this study were obtained post mortem and that they were fixed in a manner that did not necessarily reproduce normal physiological conditions. Hence the morphometric data must be assumed to reflect only the approximate dimensions of the various tissue components. Given these qualifications, however, the capillary network in the intersaccular septa of neonatal lung obviously has a relatively large mesh size (estimated intercapillary distance about $22 \mu \mathrm{m})$. Furthermore, individual capillary segments appear roughly circular in cross section and have a small diameter (about $9 \mu \mathrm{m}$ ). All of these observations suggest that the circulation of blood in the respiratory zone of neonatal lung prob- 


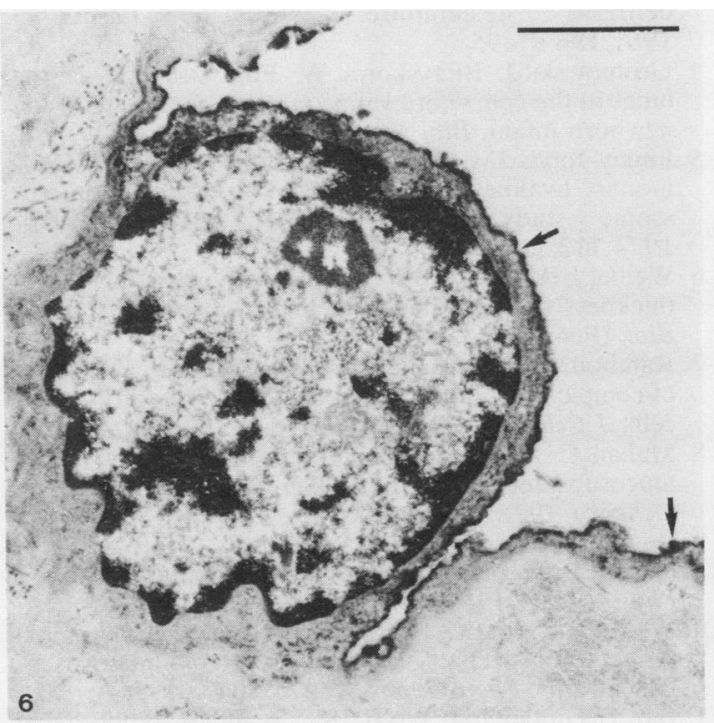

Fig 6 Tissue stained by the periodic acid-chromic acid-phosphotungstic acid procedure. The layer of reactive material associated with the luminal surface of the capillary endothelial cell is indicated by arrows. The bar represents $0.2 \mu \mathrm{m}$.

ably does not have sheet like characteristics of the type suggested for adult lung by Fung and Sobin. ${ }^{15}$

The air-blood barrier of the neonatal lung displays several interesting features. Many of the pulmonary capillaries bulge into the terminal saccules and thus expose a relatively large surface to the air. Yet, surprisingly, in many of these capillaries the nuclei of the endothelial cells lie in areas of the wall adjacent to the saccule. Their presence in this location obviously hinders the diffusion of gases during life. On the other hand, the overall thickness of the

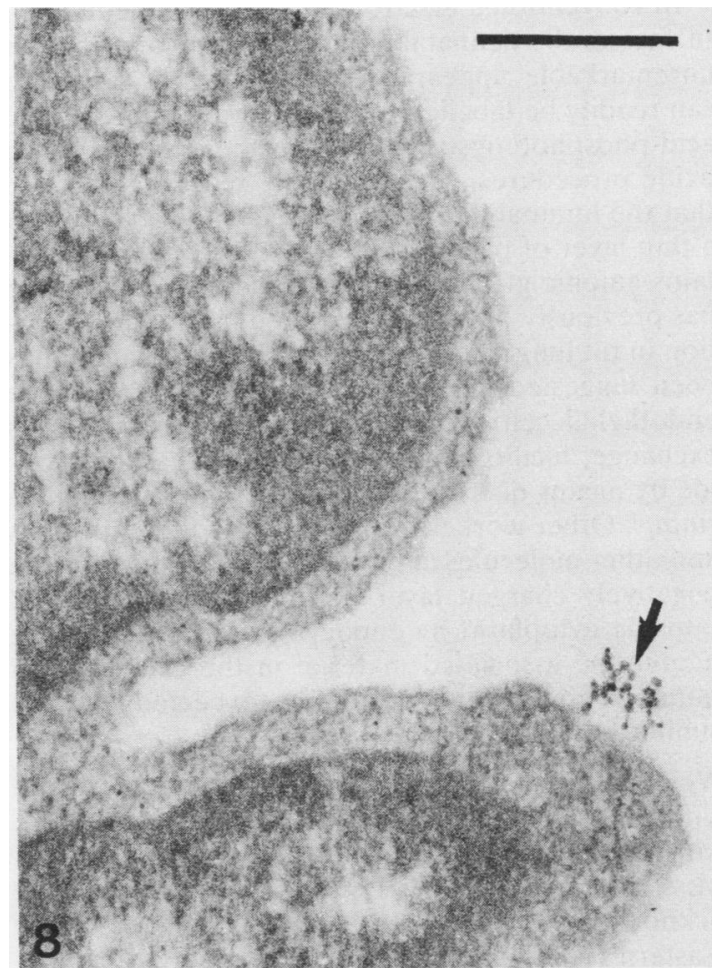

Fig 8 Control tissue pretreated with thionyl chloride and then immersed in a solution of colloidal iron oxide. Only a few particles of stain (arrow) are associated with the capillary endothelium. The bar represents $0.05 \mu \mathrm{m}$.

air-blood barrier is very low. The arithmetic mean value obtained in the present study was $1.84 \mu \mathrm{m}$, a figure that lies within the range observed in adult human lung $(1.35-3.28 \mu \mathrm{m})^{16}$ and that in a series of adult mammals (pig $1.90 \mu \mathrm{m}$; mouse $1.27 \mu \mathrm{m}$ ). ${ }^{17}$

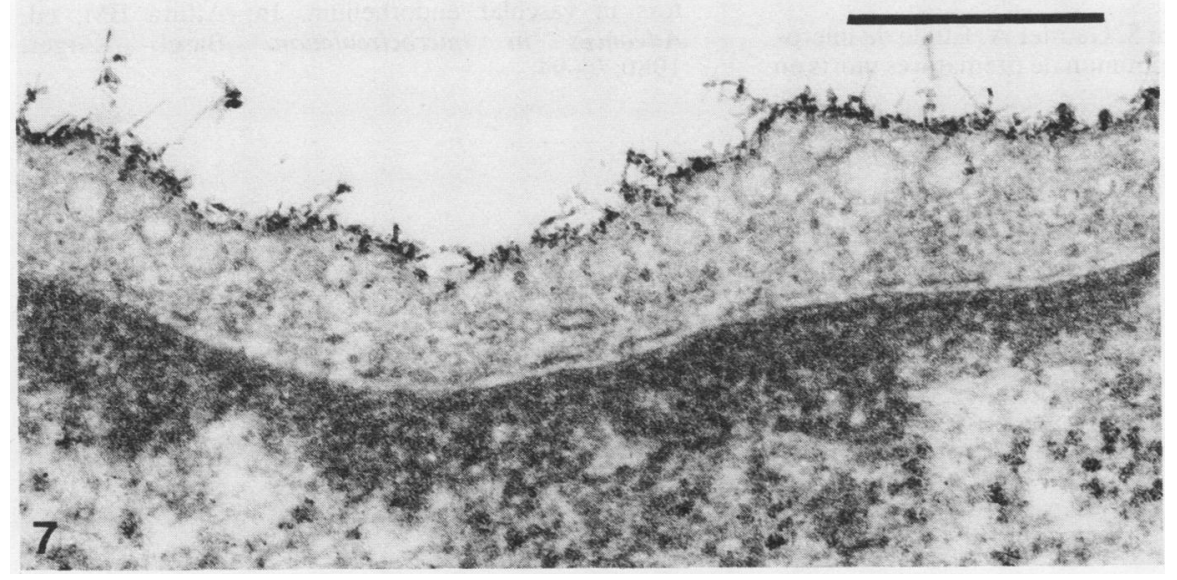

Fig 7 Tissue labelled with colloidal iron oxide. Stain particles are attached to the luminal plasma membrane of the capillary endothelial cell. The bar represents $0.05 \mu \mathrm{m}$. 
In conventional electron micrographs the luminal surface of the neonatal pulmonary capillaries has an unremarkable appearance. This surface, however, can readily be labelled by the periodic acid-chromic acid-phosphotungstic acid and the colloidal iron oxide procedures. These staining reactions indicate that the luminal plasma membranes are coated with a thin layer of periodate reactive material that contains anionic groups. A membrane associated layer has previously been demonstrated in the same location in rat lung with a ruthenium red label and it has been suggested that the net negative charge on the endothelial cell surface may be important for gas exchange, facilitating the transport of carbon dioxide by means of a local shift in the Donnan equilibrium. ${ }^{18}$ Other workers have postulated that proteins and other molecules may be selectively bound by the negatively charged layer before being transported into the cytoplasm by endocytosis. ${ }^{19}$ Obviously the membrane associated material in the capillaries of human neonatal lung could be expected to have similar functions.

We are indebted to the following for their assistance with different aspects of this study: Mr IC Clarke, Mr PG Larkin, Dr MD O'Hara, Miss A Richardson, Miss JM Smith, and Mr J White. We also gratefully acknowledge the generous support provided by the Eastern Health and Social Services Board of Northern Ireland.

\section{References}

1 Burri PH, Weibel ER. Ultrastructure and morphometry of the developing lung. In: Hodson WA, ed. Development of the lung. New York: Marcel Dekker, 1977:215-68.

2 Meyrick B, Reid LM. Ultrastructure of alveolar lining and its development. In: Hodson WA, ed. Development of the lung. New York: Marcel Dekker, 1977:135-214.

3 Campiche M, Prod'hom S, Gautier A. Etude du microscope electronique du poumon de prematures morts en deltresse respiratoire. Annales Paediatrici 1961;196: 81-95.

4 Groniowski J, Biczyskowa W. Fine structure of the lungs in the course of hyaline membrane disease of the newborn infant. Biol Neonate 1963;5:113-24.

5 Finlay-Jones JM, Papadimetrou JM, Barter RA. Pulmonary hyaline membrane: light and electron microscopic study of the early stage. J Pathol 1974;112: 117-24.

6 Weibel ER, Knight BW. A morphometric study of the thickness of the pulmonary air-blood barrier. $J$ Cell Biol 1964;21:367-84.

7 Rambourg A, Hernandez W, Leblond CP. Detection of complex carbohydrates in the Golgi apparatus of rat cells. J Cell Biol 1969;40:395-414.

8 Meban C. An electron microscopic study of the acid mucosubstance lining the alveoli of hamster lung. Histochem J 1972; 4: 1-8.

9 Bennett HS, Luft JH, Hampton JC. Morphological classification of vertebrate blood capillaries. Am J Physiol 1959;196:381-90.

10 Wolff JR, Goerz C, Bar T, Gulder FH. Common morphometric aspects of various organotypic microvascular patterns. Microvasc Res 1975;10:373-95.

11 Bar T, Gulder FH, Wolff JR. "Seamless" endothelial cells of blood capillaries. Cell Tissue Res 1984; 235: 99-106.

12 Dunnill MS. Postnatal growth of the lung. Thorax 1962;17:329-33.

13 Weibel ER. Morphometry of the human lung. Heidelberg: Springer, 1963:109.

14 Thurlbeck WM. The internal surface of nonemphysematous lungs. Am Rev Respir Dis 1967;95:76573.

15 Fung YC. Sobin SS. Pulmonary alveolar blood flow. Circulation Res 1972;30:470-90.

16 Gehr P, Bachofen M, Weibel ER. The normal human lung: ultrastructure and morphometric estimation of diffusion capacity. Respir Physiol 1978;32:121-40.

17 Meban C. Thickness of the air-blood barriers in vertebrate lungs. J Anat 1980;131:299-307.

18 Bignon J, Jaubert F, Jaurand MC. Plasma protein immunocytochemistry and polysaccharide cytochemistry at the surface of alveolar and endothelial cells in the rat lung. J Histochem Cytochem 1976;24:1076-84.

19 Buonassisi V, Colburn P. Hormone and surface receptors in vascular endothelium. In: Altura BM, ed. Advances in microcirculation. Basel: Karger, 1980:76-94. 